\title{
Strain changes on the cortical shell of vertebral bodies due to spine ageing: A parametric study using a finite element model evaluated by strain measurements
}

Proc IMechE Part H: $\mathrm{J}$ Engineering in Medicine 227(I2) I265-1274 (c) IMechE 2013

Reprints and permissions: sagepub.co.uk/journalsPermissions.nav DOI: $10.1177 / 095441$ 1913501293 pih.sagepub.com (SAGE

\author{
Yongtao Lu', Eike Rosenau ${ }^{2}$, Helge Paetzold', Anke Klein ${ }^{3}$, \\ Klaus Püschel ${ }^{3}$, Michael M Morlock' and Gerd Huber'
}

\begin{abstract}
The probability of fractures of the cortical shell of vertebral bodies increases as ageing progresses. Ageing involves all the spinal component changes. However, the effect of the spinal component ageing on the fracture risk of the cortical shell remains poorly understood. In this study, the influence of the ageing of the spinal components on cortical shell strain was investigated. A lumbar spinal specimen (L3-L5) was mechanically tested under a quasi-static axial compressive load. Clinical computed tomography images of the same specimen were used to create a corresponding finite element model. The material properties were determined by calibrating the finite element model using the L 4 cortical shell strains of the anterior centre measurement site. The remaining experiment data (axial displacement, the intra-discal pressures, L4 cortical shell strain on the lateral measurement site) were used to evaluate the model. The individual ageing process of the six spinal components (cortical shell, cancellous bone, bony endplate, posterior elements, nucleus pulposus and annulus matrix) was simulated by changing their Young's moduli and Poisson's ratios, and the effect on cortical shell strain was investigated. Results show that the cortical shell strain is more sensitive to the ageing of the cortical shell and the cancellous bone than to the ageing of the nucleus pulposus, the annulus matrix, and the bony endplates and of the posterior elements. The results can help the clinicians focus on the aspects that mainly influence the vertebral cortex fracture risk factor.
\end{abstract}

\section{Keywords}

Finite element modelling, lumbar spine, spinal ageing, cortical shell, principal strain

Date received: II February 20I3; accepted: 23 July 2013

\section{Introduction}

The cortical shell (CS) plays an important role in the load-bearing capacity of the vertebral body. As agerelated bone mass loss progresses, the load-carrying role of CS increases significantly, ${ }^{1}$ making the cortex more vulnerable to fractures. Nalla et al. ${ }^{2}$ found that the fracture in bone is locally strain-controlled and consequently strain-based failure criterion is always adopted for human cortical bones. ${ }^{3,4}$ Kayanja et al. ${ }^{5}$ found that the strain distribution along the cortex may be predictive of impending fractures. Therefore, understanding the factors which can influence the cortical strain could help reduce the risk of cortex fractures.

The normal ageing process is accompanied by changes in all components of a functional spinal unit
(FSU). The earliest age-related degeneration occurs in the intervertebral disc and this degeneration starts with a dehydration of the nucleus pulposus (NP), followed by stiffening of the annulus fibrosus and decreased disc height. ${ }^{6}$ The ageing process also involves the loss of

\footnotetext{
'Institute of Biomechanics, TUHH Hamburg University of Technology, Hamburg, Germany

${ }^{2}$ Centre for Endoprosthetics, Schön Klinik Hamburg Eilbek, Hamburg, Germany

${ }^{3}$ Department of Legal Medicine, University Medical Center HamburgEppendorf, Hamburg, Germany
}

\section{Corresponding author:}

Yongtao Lu, Institute of Biomechanics, Hamburg University of Technology, Denickestrasse 15, 21073 Hamburg, Germany. Email: yongtao.lu@tuhh.de 


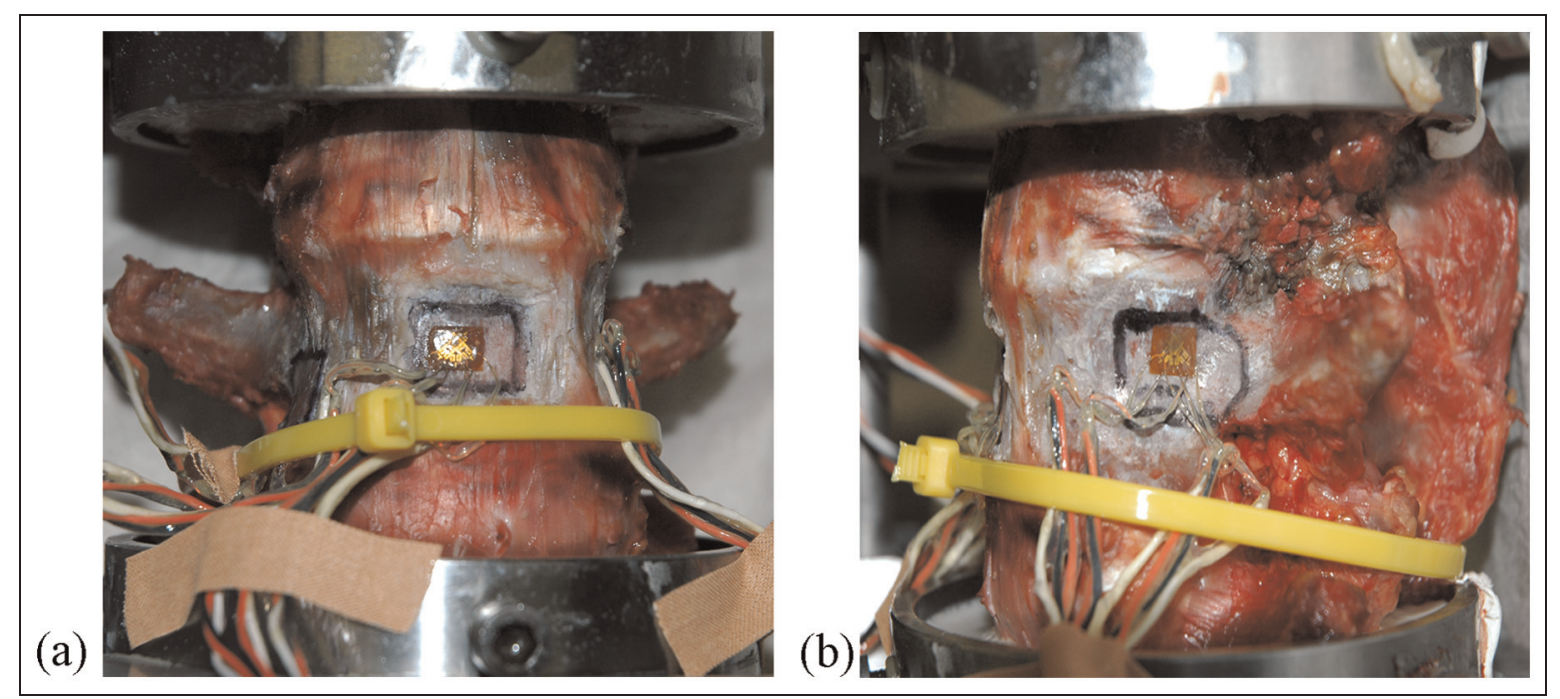

Figure I. Lumbar spinal specimen (L3-L5) mounted in the material testing machine with bonded triple strain gauge rosettes on the (a) anterior centre and (b) lateral right locations of the L4 cortex.

bone mineral density (BMD) possibly leading to osteoporosis. Previous authors used the finite element (FE) method to simulate the formation of osteoporosis, ${ }^{7}$ the intervertebral disc degeneration ${ }^{8}$ and the ageing of one FSU. ${ }^{9}$ Their approach is to modify either only the material properties or both the geometry and material properties of involved tissues. However, if several parameters in one model are changed to simulate the ageing scenario, it is questionable how the variations of each individual parameter influence the overall results. In terms of fracture prediction, this would be the CS strain. Due to the experimental limitations, it is difficult to mimic the individual in vivo ageing of spinal components in vitro and consequently it is still unclear how the ageing of each spinal component influences the probability of CS fracture. Therefore, the purpose of this study is to investigate the CS strain changes due to the ageing of each spinal component using a FE model.

\section{Materials and methods}

\section{In vitro axial compression testing}

A lumbar spinal specimen (L3-L5) from a 37-year-old male donor was harvested for mechanical testing. No visible degenerations were observed on the spine, and diseases influencing the muscular-skeletal system were not present. The specimen was wrapped into a towel moistened with physiological salt solution, doublesealed in plastic bags and kept frozen below $-20^{\circ} \mathrm{C}$ until testing. The specimen was thawed at room temperature for about $10 \mathrm{~h}$ before preparation. Muscles and the intertransverse ligaments were removed. Care was taken not to injure the intervertebral discs and the remaining ligamentous soft tissues. The superior (L3) and inferior (L5) vertebrae were potted into stainless steel fixtures. A polyurethane resin was chosen for potting (RenCast ${ }^{\circledR}, \mathrm{FC} 53$ Isocyanate FC 53 Polyol, Huntsman Advanced Materials $\mathrm{GmbH}$, Basel, Switzerland). The lateral right and anterior centre area of the L4 cortex were cleaned and prepared for strain gauge application. Triple strain gauge rosettes were glued on both strain measurement spots (WK-13-060WR-350, Vishay Micro-Measurements, Raleigh, NC, USA; Figure 1). Needle pressure transducers were inserted in both discs approaching from the ventromedial direction (Model $8 \mathrm{CT} / 4 \mathrm{~F} / \mathrm{SS}$, Gaeltec, Isle of Skye, Scotland). Care was taken to place the tip in the centre of NP. After preparation, the specimen was mounted in a servo-hydraulic material testing system (MTS Bionix 858.2, MTS Corp., Eden Prairie, MN, USA). The lower fixture of the specimen was rigidly fixed to a 6-degree-of-freedom load-cell (Model No. 30031, Huppert, Herrenberg, Germany). The upper fixture was only allowed to move in the vertical and the spinal anterior-toposterior directions ( 2 degrees of freedom).

Compressive axial loading cycles from $0 \mathrm{~N}$ to $2 \mathrm{kN}$ and back to $0 \mathrm{~N}$ with a cyclic duration of $200 \mathrm{~s}$ were performed in order to achieve the quasi-static loading, which is the underlying basis for all activities like changing posture or carrying any kind of loads. Two loading cycles were performed in order to fade out the transient responses which were caused by the initial start of the experiments. ${ }^{10}$ Then after the complete testing scenarios (shear, dynamic, etc.), the quasi-static loading was repeated but further changes could not be observed. Therefore, in this article the data from the second loading cycle were processed for the strain analysis.

The outputs from the mechanical testing were axial displacement (superior-inferior direction), pressures on both intervertebral discs and strains from the two strain gauge rosettes. The strains measured were transferred to the principal strains. 


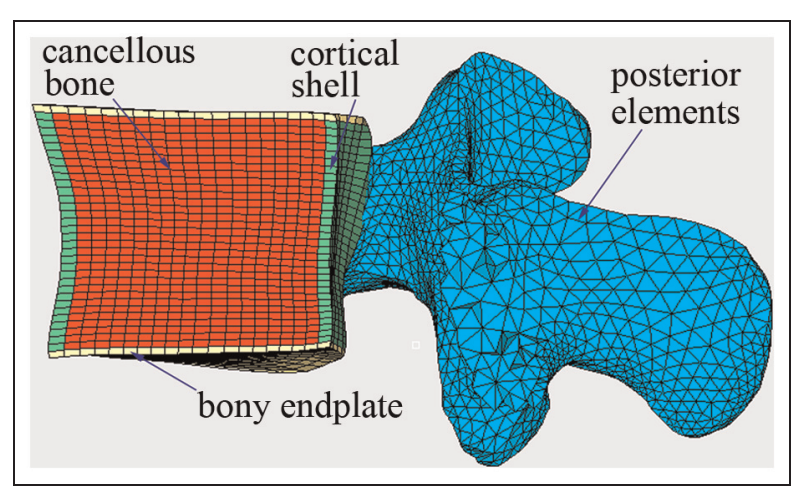

Figure 2. Finite element model of the L4 vertebra (the model is sectioned in the midsagittal plane to reveal the internal structure).

\section{FE model of the lumbar spine segment}

FE mesh of the spine segment. The lumbar specimen was scanned prior to the mechanical testing with a clinical image resolution of $0.246 \mathrm{~mm}$ and a slide thickness of $1.0 \mathrm{~mm}$ (Siemens SOMATOM Volume Zoom, Siemens, Erlangen, Germany). The computed tomography (CT) data were used to derive the geometric information for the FE model. The CT image data were processed using a visualization program (Avizo, Version 5.0, Mercury Computer Systems, Inc., Burlington, MA, USA). A CAD Program (Pro/ENGINEER, Wildfire 5.0, Parametric Technology Corporation, Needham, MA, USA) and a FE preprocessor software (HyperMesh, Version 10.0, Altair Engineering Inc., Troy, MI, USA) were used to generate the FE mesh, which was exported into a FE solver (Abaqus, Version 6.10-1, Dassault Systemes SIMULIA Ltd, Providence, RI, USA).

The FE vertebral model (Figure 2) consisted of the $\mathrm{CS}$, the cancellous bone (CB), the bony endplates (BEs) and the posterior structures with the facet joints. The endplate cannot be clearly segmented from the clinical CT images. Therefore, the thickness of the endplates was taken from literature and set to $0.8 \mathrm{~mm} .{ }^{11}$ The thickness of the CS was estimated from the CT images and set to $1.4 \mathrm{~mm}$ for the anterior and $1.2 \mathrm{~mm}$ for the posterior part. The FE facet joint model included the subchondral bone, the capsular ligaments and the articular cartilage. Joint contact was simulated using the surface-to-surface contact method, which is a general contact formulation integrated in Abaqus to model contact between two surfaces. In this article, it is used to simulate the contact between the two articular cartilage surfaces. Joint friction was assumed to be $0 .{ }^{12}$ Cartilage thickness was set to $0.2 \mathrm{~mm} .{ }^{13}$ For each facet joint, 26 capsular ligaments were modelled and each ligament was represented by three-dimensional (3D), unidirectional, non-compressible truss elements with a cross-sectional area of $48.4 \mathrm{~mm}^{2} .^{14}$

The FE intervertebral disc model (Figure 3) consisted of the NP and the annulus, whereas the annulus was assumed to be composed of a homogeneous matrix

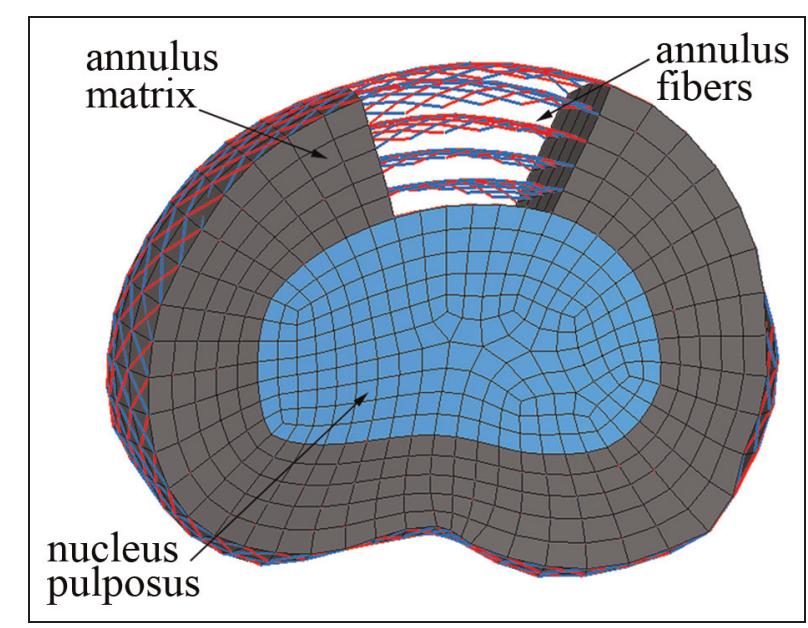

Figure 3. Finite element model of the L3-L4 intervertebral disc (part of the annulus matrix is masked to reveal the annual fibres).

reinforced by a collagen fibre network. Six crisscross fibre layers were defined in the radial direction. The angulations of the fibres varied from $\pm 23^{\circ}$ (to the horizontal plane) at the posterior side to $\pm 43.5^{\circ}$ at the anterior side. ${ }^{15}$ The relative volume content of the fibres with respect to the surrounding matrix was assumed to vary from $23 \%$ at the outermost layer to $5 \%$ at the innermost fibre layer. ${ }^{16}$ The cross-sectional areas of annulus fibres were calculated based on the fibre volume fraction assumed for each layer, the number of fibre elements used, the length of the fibres and the volume of each annulus layer. The calculated fibre crosssectional areas for each layer are listed in Table 1. The collagen fibres were represented by $3 \mathrm{D}$, unidirectional truss elements with no compression feature (T3D2). The internal structure of the disc could not be determined from CT images. The ratio of the NP volume to the total disc volume was assumed to be $31.2 \%$ (L3L4) and $32.1 \%$ (L4-L5), which match the reported values. ${ }^{17}$ The NP was shifted posteriorly by $3.8 \mathrm{~mm}$ from the disc centre ${ }^{18}$ and modelled as an incompressible material.

The developed spine model was meshed with 204,114 elements (Figure 4). To check the mesh convergence, a second FE model was developed, where the meshes in the anterior part (anterior body and intervertebral disc) of the spinal segment were refined. The element size in the spinal posterior and the fixation parts is around $1.2 \mathrm{~mm}$ and quadratic element C3D10 is used for these two parts to increase the accuracy. Besides, these two structures do not play a big role on the CS strains under the small compression scenario. Therefore, the meshes in these two parts were not refined in the convergence analysis. Due to the special modelling technique applied in the FE model, there is no individual solid for each component (CB, CS, NP, etc.). Therefore, remeshing the solids into different mesh densities cannot be applied in the model. Nevertheless, the element 'split' function in HyperMesh was used to split one element 
Table I. Cross-sectional area $\left(\mathrm{mm}^{2}\right)$ for different layers of the annulus fibres.

\begin{tabular}{lllllll}
\hline & Innermost layer & Second layer & Third layer & Fourth layer & Fifth layer & Outermost layer \\
\hline L3-L4 disc & $0.105(5 \%)$ & $0.173(9 \%)$ & $0.270(13 \%)$ & $0.380(17 \%)$ & $0.478(20 \%)$ & $0.190(23 \%)$ \\
L4-L5 disc & $0.074(5 \%)$ & $0.125(9 \%)$ & $0.194(13 \%)$ & $0.270(17 \%)$ & $0.344(20 \%)$ & $0.411(23 \%)$ \\
\hline
\end{tabular}

Values in parentheses represent the volume fraction of collagen fibres.

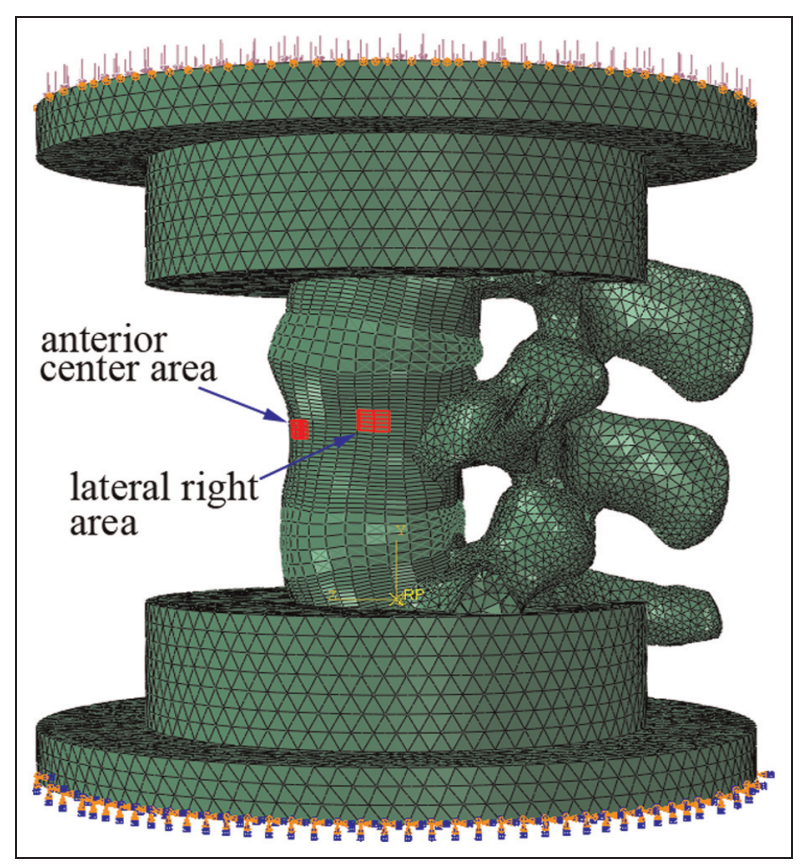

Figure 4. Finite element representation of the experimental testing (highlighted elements represent the area where strain gauge rosettes were attached; arrows on the top represent the applied pressure).

into four elements. This resulted in a refined model (Figure 5) with 552,896 elements and this model is referred as 'model B'. The model with 204,114 elements is referred as 'model A'. The output data from these two models were compared (Table 2) and it can be seen that the difference was less than $5 \%$ in all parameters. Therefore, 'model A' was considered converged and was used in this article because of its less computation time.

Determination of the material property parameters. There are 11 components (CS, CB, posterior elements (PE), $\mathrm{BE}$, annulus matrix (AM), annulus fibres, NP, capsular ligaments, facet joint cartilage, Polyol resin and metal fixation) in the formulated FE model. The material properties of each component are assumed to be linear elastic and isotropic, which yields 22 independent parameters, that is, Young's modulus and Poisson's ratio for each component. Poisson's ratios are assumed to be single values and are taken from the literature. Young's moduli for polyurethane resin and the metal fixation are taken from the literature. Young's moduli for the spinal components are specimen specific and were determined using the method below.

First, based on the fact that the tested specimen was from a young healthy donor, Young's modulus ranges for all spinal components were taken from the literature. Since the interest in this study is the strain changes in the L4 CS, a Young's modulus sensitivity study of the L4 CS strain was performed. Appropriate

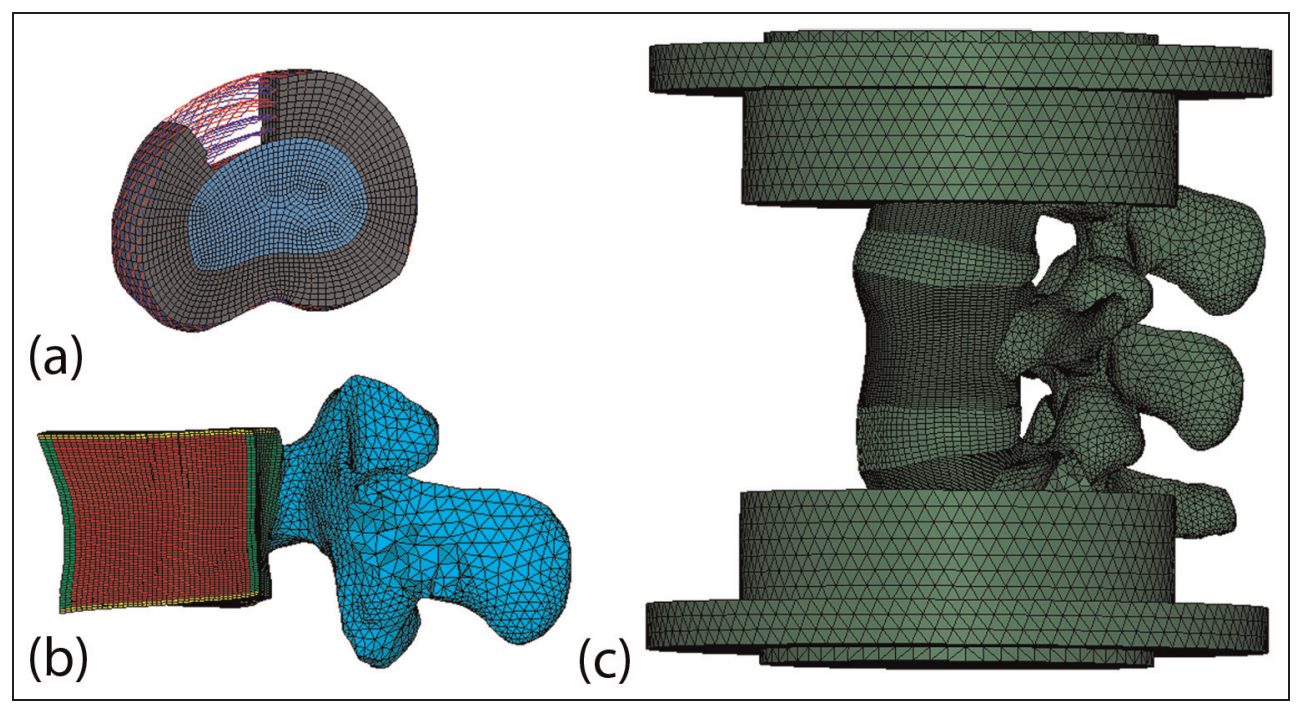

Figure 5. L3-L5 FE model with finer meshes. (a) L3-L4 intervertebral disc (part of the annulus matrix is masked to reveal the annulus fibres), (b) L4 vertebra (the model is sectioned to reveal the internal structure) and (c) the whole spine model. 
Table 2. Mesh convergence study data.

\begin{tabular}{llllllll}
\hline & $\begin{array}{l}\text { Axial } \\
\text { displacement } \\
(\mathrm{mm})\end{array}$ & $\begin{array}{l}\text { L3-L4 discal } \\
\text { pressure } \\
(\mathrm{MPa})\end{array}$ & $\begin{array}{l}\text { L4-L5 discal } \\
\text { pressure } \\
(\mathrm{MPa})\end{array}$ & $\begin{array}{l}\varepsilon_{1} \text { : anterior } \\
\text { centre } \\
\text { spot }(\mu \varepsilon)\end{array}$ & $\begin{array}{l}\varepsilon_{2} \text { : anterior } \\
\text { centre } \\
\text { spot }(\mu \varepsilon)\end{array}$ & $\begin{array}{l}\varepsilon_{1} \text { : lateral } \\
\text { right } \\
\text { spot }(\mu \varepsilon)\end{array}$ & $\begin{array}{l}\varepsilon_{2} \text { : lateral } \\
\text { right } \\
\text { spot }(\mu \varepsilon)\end{array}$ \\
\hline Model A & -2.34 & 1.46 & 1.56 & 415.91 & -466.26 & 649.09 & -798.01 \\
Model B & -2.32 & 1.49 & 1.62 & 403.22 & -458.54 & 634.64 & -781.48 \\
\hline
\end{tabular}

$\varepsilon_{1}$ represents the principal tensile strain and $\varepsilon_{2}$ represents the principal compressive strain.

Table 3. Calibration of the FE predictions against the experimental data.

\begin{tabular}{lll}
\hline & $\begin{array}{l}\varepsilon_{1}: \text { anterior } \\
\text { centre spot }(\mu \varepsilon)\end{array}$ & $\begin{array}{l}\varepsilon_{2}: \text { anterior } \\
\text { centre spot }(\mu \varepsilon)\end{array}$ \\
\hline Experimental data & 403.36 & -441.62 \\
FE prediction & 415.91 & -466.26 \\
\hline
\end{tabular}

FE: finite element.

boundary conditions were applied in the FE spinal model to simulate the in vitro mechanical test situation. The principal strains on the outer surface nodes of the FE mesh, which were covered by the respective strain gauge rosette in the experiment, were averaged. Then Young's moduli of the spinal components were varied individually and the resulting principal strains were compared. The sensitivity study showed that Young's modulus variations of the $\mathrm{PE}$, the $\mathrm{BE}$, the annulus fibres, the capsular ligaments and the facet joint cartilage had little influence on the L4 CS strain. This justified the use of the typical values from the literature.

After Young's modulus sensitivity study, the remaining uncertain parameters were Young's moduli of the $\mathrm{CS}$, the $\mathrm{CB}$, the AM and the NP. A calibration study was performed to determine their values, and the experimental data of L4 CS strains in the anterior centre position were used. Based on the literature ${ }^{9,14,19-22}$ and the fact that the created model is from a young and healthy male donor, the ranges for varying Young's moduli of the CS, the CB, the AM and the NP were [10000.0, 12000.0] $\mathrm{MPa},[100.0,344.0] \mathrm{MPa},[0.1,5]$
MPa and [0.1, 3.4] MPa, respectively. The calibration process was stopped when both predicted strains best matched the corresponding experimental strains (Table 3). The determined material properties are listed in Table 4.

\section{Numerical simulation of the spine ageing}

The evaluated FE spinal model was used to investigate the effect of the age-related changes of each spinal component on the CS strains. The age-related changes of the bony components were simulated by reducing their Young's moduli. For the fully aged bone, a decrease by $66 \%$ of Young's modulus for the CB and by $33 \%$ for the remaining bony structures was applied. ${ }^{30,31}$ Young's moduli chosen for the mildly aged bone were linear interpolated between the healthy and fully aged bone. ${ }^{31}$ This yielded a $50 \%$ decrease of Young's modulus for the mildly aged CB and a $25 \%$ decrease for the remaining bony structures. This spine ageing simulation technique and similar bone modulus values can be found in Polikeit et al., ${ }^{7}$ Kurutz and Oroszváry's studies.

The age-related degeneration of spinal disc involves the dehydration of nucleus and the hardening of both nucleus and AM. Due to dehydration, the nucleus is changing from an almost incompressible gel-like substance to a more fibrous tissue. This phenomenon is simulated by decreasing Poisson's ratio of NP. The hardenings of nucleus and AM were modelled by increasing their Young's moduli. ${ }^{9,32,33}$ Young's moduli of the six spinal components under different grades of

Table 4. Material properties for each component in the FE spinal model.

\begin{tabular}{lllll}
\hline Material & Element type & Young's modulus (MPa) & Poisson's ratio & References \\
\hline Cortical shell & C3D8 Hex & 12000.0 & 0.300 & Burstein et al. $^{19}$ \\
Cancellous bone & C3D8 Hex & 150.0 & 0.300 & Lindahl $^{20}$ \\
Posterior elements & C3DI0 Tetra & 3500.0 & 0.250 & Shirazi-Adl et al. $^{23}$ \\
Bony endplate & C3D8 Hex & 10000.0 & 0.300 & Grant et al. $^{24}$ \\
Annulus matrix & C3D8 Hex & 4.2 & 0.450 & Yamada and Evans $^{21}$ \\
Annulus fibres & T3D2 & 500.0 & 0.300 & Morgan $^{25}$ \\
Nucleus pulposus & C3D8 Hex & 1.0 & 0.499 & Périé et al. $^{22}$ \\
Capsular ligaments & T3D2 & 24.4 & 0.300 & Little and Khalsa $^{26}$ \\
Facet joint cartilage & S3 & 10.4 & 0.400 & Elder et al. $^{27}$ \\
FC 53 Polyol resin & C3DI0 Tetra & 2880.0 & 0.300 & RenShape Solutions $^{28}$ \\
Metal fixation & C3DI0 Tetra & 207000.0 & 0.300 & MacGregor et al. $^{29}$ \\
\hline
\end{tabular}


Table 5. Young's moduli of spinal components for different grades of spinal ageings.

\begin{tabular}{lllllll}
\hline Grade of ageing & $\begin{array}{l}\text { Cortical } \\
\text { shell (MPa) }\end{array}$ & $\begin{array}{l}\text { Cancellous } \\
\text { bone (MPa) }\end{array}$ & $\begin{array}{l}\text { Posterior } \\
\text { elements (MPa) }\end{array}$ & $\begin{array}{l}\text { Nucleus } \\
\text { pulposus (MPa) }\end{array}$ & $\begin{array}{l}\text { Annulus } \\
\text { matrix (MPa) }\end{array}$ & $\begin{array}{l}\text { Bony } \\
\text { endplate (MPa) }\end{array}$ \\
\hline Healthy & 12000.0 & 150.0 & 3500.0 & 1.0 & 4.0 & 10000.0 \\
Mildly ageing & 9000.0 & 75.0 & 2625.0 & 1.6 & 6.0 & 7500.0 \\
Fully ageing & 8000.0 & 35.0 & 2345.0 & 2.8 & 8.0 & 6700.0 \\
\hline
\end{tabular}

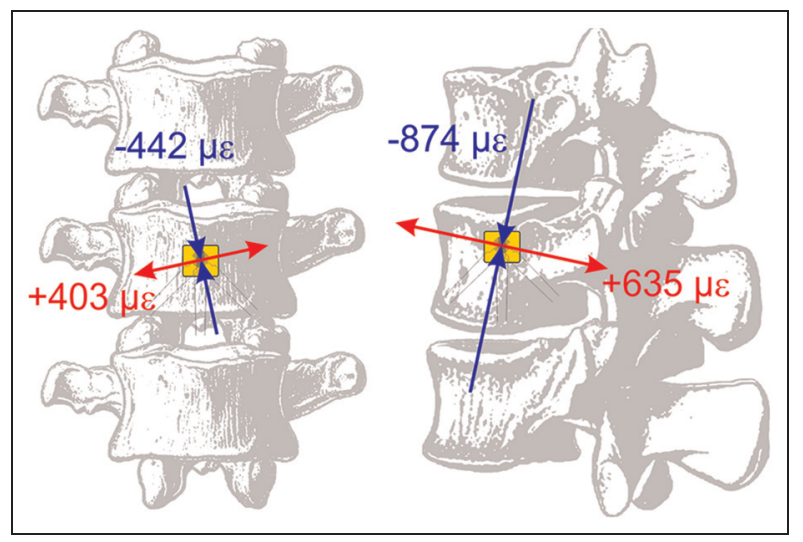

Figure 6. Principal strain distributions on the two measurement spots. The rectangular represents the strain gauge rosettes. The compressive principal strains and the tensile principal strains are also shown.

ageing are listed in Table 5. For the mildly and fully degenerated NP, Poisson's ratios were set to 0.4 and $0.3,{ }^{9}$ respectively, which corresponds to the bulk moduli of $2.67 \mathrm{MPa}$ and $2.33 \mathrm{MPa}$.

The individual ageing of the six spinal components including $\mathrm{CS}, \mathrm{CB}, \mathrm{PE}, \mathrm{NP}, \mathrm{AM}$ and $\mathrm{BE}$ was simulated using the evaluated FE model. For the ageing simulation of each spinal component, its material properties were modified from the healthy state to the mildly aged and further to the fully aged states, while the elastic constants of the other components were kept in the healthy state. The loading and boundary conditions were kept the same as those used in the mechanical testing.

\section{Results}

\section{Experimental testing results}

The principal strain distributions on both measurement spots are plotted in Figure 6, where both the magnitudes and angles of the principal strains are shown.

\section{Evaluation of the FE model}

The loading and boundary conditions applied in the mechanical testing were simulated in the FE model. The experimental data of the axial displacement, the intra-discal pressures and the principal strains at the lateral right strain measurement spot were used to evaluate the calibrated FE spinal model. The evaluated result is shown in Table 6. It can be seen that the developed FE spinal model gives good predictions of the specimen behaviour under axial compression. The evaluation of the FE model is related to a young and healthy case.

\section{Effect of the spinal ageing on the CS strains}

The principal compressive and tensile strains in the anterior centre area from each simulation are plotted in Figure 7. The strains in the lateral right area are plotted in Figure 8.

The ageing of the CS increased both the principal compressive and tensile strains on both measurement spots (Figures 7 and 8). The ageing of the CB increased the principal tensile strain in the anterior centre area and increased the principal compressive strain in the lateral right area. The degeneration of the NP decreased the principal tensile strains on both measurement spots, but increased the principal compressive strains on both measurement spots. From Figures 7 and 8, it can be concluded that the CS strains were more sensitive to the ageing of the $\mathrm{CS}$ and the $\mathrm{CB}$ than to the ageing of the $\mathrm{NP}$, the AM, the BE and the PE.

A stress-related mechanical analysis was also performed. Since the principal compressive strains are of more interest than the tensile strains, only the principal compressive stresses were investigated (Figure 9). It can be seen from Figures 7 to 9 that the compressive stresses have a correlation with the corresponding compressive strains and the sensitivity of the compressive stresses to the individual component ageing is similar to that of the compressive strains. However, this

Table 6. Evaluation of the FE predictions against the experimental data.

\begin{tabular}{llllll}
\hline & $\begin{array}{l}\text { Axial } \\
\text { displacement }(\mathrm{mm})\end{array}$ & $\begin{array}{l}\text { L3-L4 discal } \\
\text { pressure }(\mathrm{MPa})\end{array}$ & $\begin{array}{l}\text { L4-L5 discal } \\
\text { pressure }(\mathrm{MPa})\end{array}$ & $\begin{array}{l}\varepsilon_{1} \text { : lateral right } \\
\text { spot }(\mu \varepsilon)\end{array}$ & $\begin{array}{l}\varepsilon_{2} \text { : lateral right } \\
\text { spot }(\mu \varepsilon)\end{array}$ \\
\hline Experimental data & -2.47 & 1.43 & 1.58 & 634.75 & -873.82 \\
FE prediction & -2.34 & 1.46 & 1.56 & 649.09 & -798.01 \\
\hline
\end{tabular}

FE: finite element. 


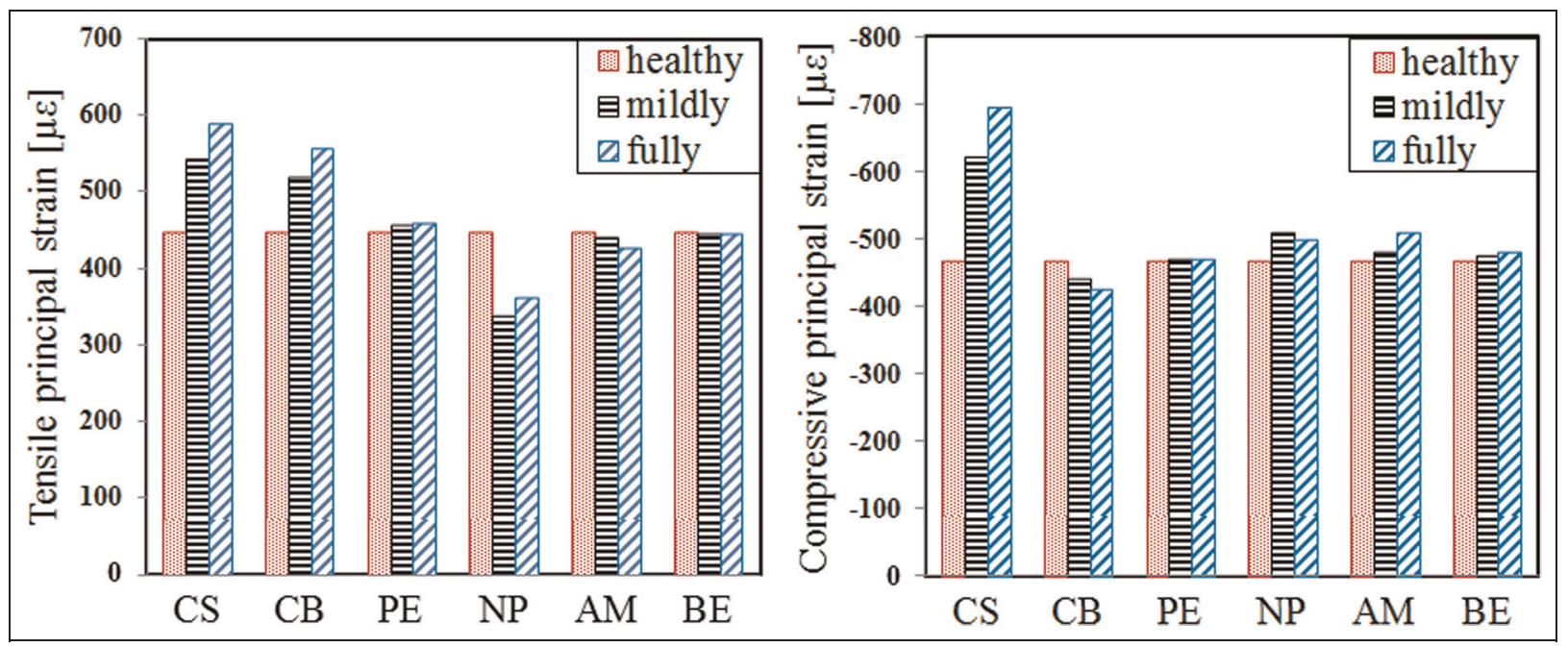

Figure 7. Effect of the individual ageing of the six spinal components (CS: cortical shell; CB: cancellous bone; PE: posterior elements; NP: nucleus pulposus; AM: annulus matrix; BE: bony endplate) on the principal strains in anterior centre area.

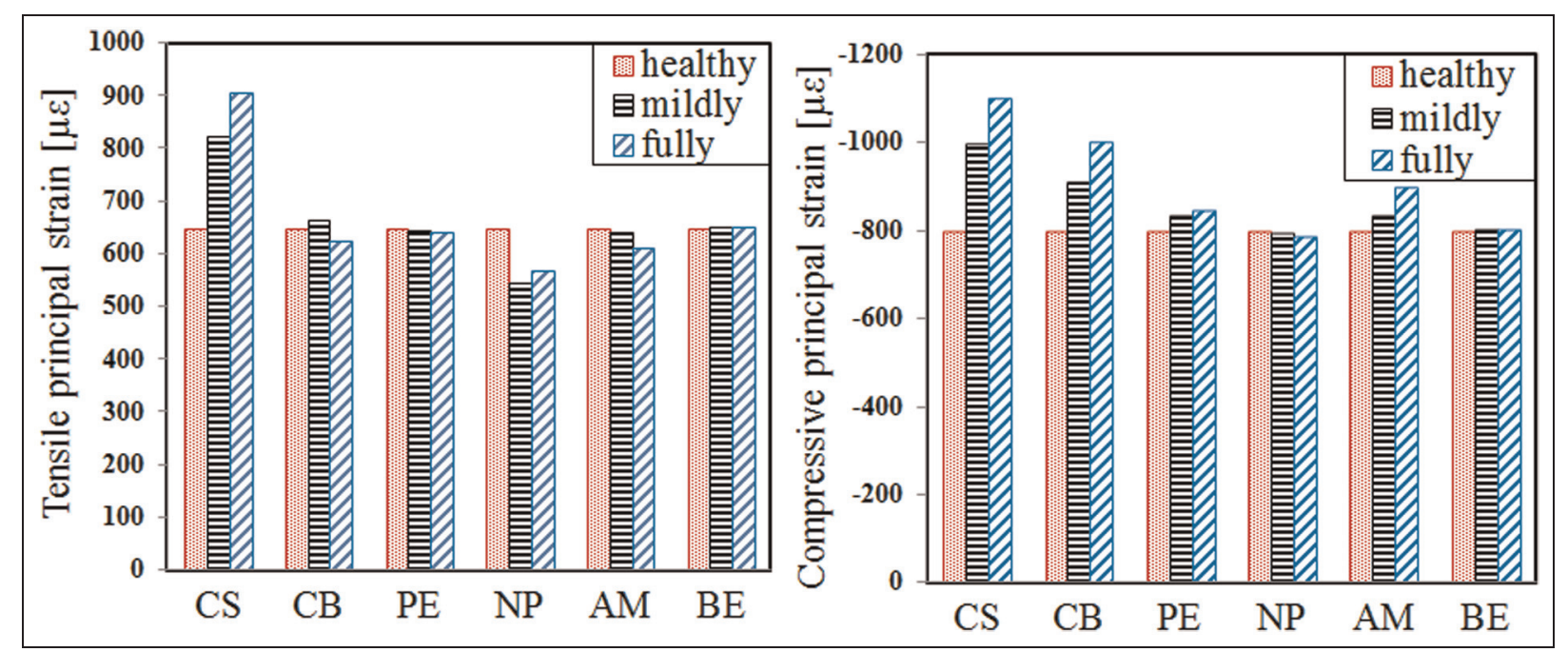

Figure 8. Effect of the individual ageing of the six spinal components (CS: cortical shell; CB: cancellous bone; PE: posterior elements; NP: nucleus pulposus; AM: annulus matrix; BE: bony endplate) on the principal strains in lateral right area.

phenomenon does not apply for the ageing of the CS because Young's modulus of the CS was also changed in this case.

\section{Discussion and conclusion}

This study showed that the CS strains are more sensitive to the ageing of the $\mathrm{CS}$ and the $\mathrm{CB}$ than to the ageing of the NP, the AM, the endplate and the PE. Although the above phenomenon is based on the calculations where the specimen was only under elastic deformations, it is assumed that all the strains will increase proportionally with the increase in applied load until the failure strain is reached. Among vertebral deformities, the prevalence of wedge fractures is the highest among others, ${ }^{34}$ which makes the vertebral anterior cortex a site of interest for understanding the vertebral fracture mechanisms. This study indicates that the age-related material property changes of the cortex and $\mathrm{CB}$ are the two main factors that influence the cortex fracture risk factor, and the age-related material property changes of the disc are not a major concern to the cortex facture - at least in a quasi-static loading scenario. The age-related material property changes of the cortex and $\mathrm{CB}$ are due to the BMD loss. ${ }^{31}$ Therefore, to reduce the cortex fracture risk factor, measures of slowing the BMD loss or maintaining and increasing BMD should be taken, for example, supplementation of vitamin $\mathrm{D},{ }^{35}$ taking bisphosphonate for an appropriate term ${ }^{36}$ and so on.

Comparing the measured strain data with those measured by Hongo et al. ${ }^{37}$ and Shah et al. ${ }^{38}$ it can be found out that our data are mostly within the ranges of Shah et al.'s measurements but are smaller than Hongo 


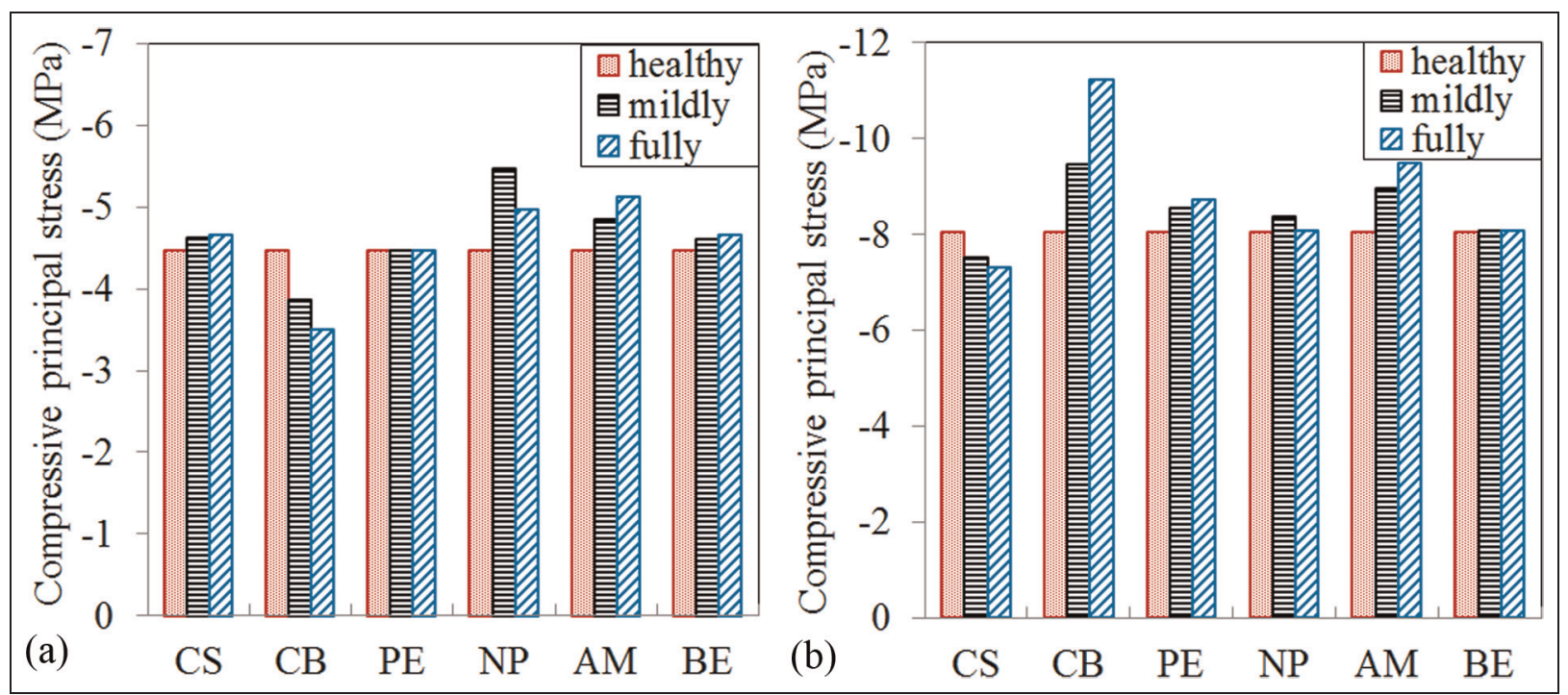

Figure 9. Effect of the individual ageing of the six spinal components (CS: cortical shell; CB: cancellous bone; PE: posterior elements; NP: nucleus pulposus; AM: annulus matrix; BE: bony endplate) on the principal compressive stresses in (a) anterior centre and (b) lateral right spots.

et al.'s measurements. This could be due to the differences in sample ages. Hongo et al. used specimens with an average age of 64.7 years. Shah et al. used specimens with the age ranging from 16 to 41 years. Furthermore, the strain gauge attachment locations and the testing protocol could also contribute to the differences. However, the same strain distribution trends were found among these three studies, that is, the compressive strains are bigger than the tensile strains when measured at the same location; both compressive and tensile strains are bigger in the lateral right spot than those in the anterior centre spot.

The strain gauge technique to investigate the strain distribution on human spine has been used by several authors. ${ }^{37-39}$ However, due to the experimental limitations, experiments only deliver local insight into the structure. FE modelling has become an important tool for analysing and predicting the stress and strain in bone because it delivers both local and global information about spinal mechanics. Experimental validation is needed to determine the quality of FE predictions. In most experimental spinal investigations, only global parameters were measured, for example, the range of motion (ROM) and the reaction force or the intradiscal pressure. Consequently, the developed FE models ${ }^{13,40,41}$ were evaluated and applicable only with respect to these parameters. However, these parameters mainly focus on the intervertebral disc and are hardly adequate for evaluating the deformation of vertebral body. To do so, several researchers ${ }^{42-44}$ have used the localized strain data measured on the vertebral body. However, it can be assumed that the strain data from one localized area are inadequate to provide a rigorous evaluation on the CS deformation. In this study, the spinal FE model was evaluated not only by the global parameters but also by two localized CS strains. The other advantage of this study is the experiment testing design. Bisegment spinal specimen is used instead of embedding one vertebral body in the metal fixation. The loading is transferred to the investigating vertebra via two intervertebral discs, which makes the strain distribution of the investigating vertebra closer to the in vivo situation.

Some limitations of this study have to be discussed. First, linear elastic, isotropic materials were used for all the spinal components. However, experimental studies showed that cortical bone is orthotropic, ${ }^{45} \mathrm{CB}$ is anisotropic and heterogeneous, ${ }^{46}$ and intervertebral disc is biphasic. ${ }^{47}$ Consequently, anisotropic elasticviscoplastic bone model ${ }^{48}$ and porohyperelastic disc model $^{49}$ are available in the literature. Experimental work showed that the intervertebral disc has a linear region within $20 \% \operatorname{strain}^{22,47,50}$ and the disc degeneration makes the elasticity more linear. ${ }^{32}$ In this article, the maximal strain occurred in the disc is around $20 \%$ when the spinal segment is under $2 \mathrm{KN}$ axial compression load. Furthermore, the viscoelastic properties could be ignored in the quasi-static loading scenario when the transient responses have faded out. ${ }^{10}$ So in this study, linear elastic materials for the disc could be appropriate. However, for more complex loading scenarios (dynamic, multiaxial, etc.), the use of advanced material properties in the FE model would be needed to account for the in vitro and in vivo condition. Second, in the FE spinal model, the thickness of CS was estimated from the clinical CT images, which make the cortical wall thicker. It is highly likely that the CS strain has a big correlation with the CS thickness. However, in this model which is evaluated by the strain measurements, the thickening of the CS is compensated by the decreased Young's modulus. This compensation might not severely influence the conclusion made in 
this article. In future, it would be interesting to create a geometrically accurate spinal model from highresolution CT images to verify this assumption. Third, the endplates anatomically consist of two parts: the high-strength external ring (BE) and the low-strength internal circular cartilaginous endplate covering the inner two-thirds of the annulus and the entire NP. However, in this study the cartilaginous endplate was treated as BE. As the material moduli and their agerelated reduction ratio of the cartilaginous endplate are similar to that of the $\mathrm{CB}$, consequently, their effect on the vertebral strain could be different from that of the applied BE. The future FE spinal model should be refined to incorporate both the bony and cartilaginous endplates into the model. Finally, in this study the agerelated changes were simulated only by modifying the material properties of spinal components. However, the spinal ageing is also associated with some geometrical parameter alterations, for example, the decrease of disc height ${ }^{51}$ the decrease of the diameter of nucleus ${ }^{6}$ and so on. All these aspects have to be considered in the future to yield more realistic simulations of spinal ageing.

In conclusion, this article demonstrated that the vertebral CS strain is more sensitive to the ageing of the cortex and $\mathrm{CB}$ than to the ageing of the NP, the AM, the BEs and of the PE. Therefore, to reduce the cortex facture risk factor due to ageing, people should focus more on slowing the BMD loss or maintaining the BMD, for example, supplementation of vitamin D and bisphosphonate, and so on.

\section{Acknowledgements}

We would like to thank Dipl.-Ing. Miklós Ivicsics for the help on the writing of the mechanical testing part and $\mathrm{Mr}$ Andi Purnomo $\mathrm{Ng}$ for the help with the finite element model generation.

\section{Declaration of conflicting interests}

The authors declare that there is no conflict of interest.

\section{Funding}

This study was supported by the Federal Ministry of Education and Research (BMBF), Germany; Federal Institute for Occupational Safety and Health (FIOSH), Germany; and the State of Hamburg (FHH, BSG).

\section{References}

1. Cao KD, Grimm MJ and Yang KH. Load sharing within a human lumbar vertebral body using the finite element method. Spine (Phila Pa 1976) 2001; 26(12): E253-E260.

2. Nalla RK, Kinney JH and Ritchie RO. Mechanistic fracture criteria for the failure of human cortical bone. Nat Mater 2003; 2(3): 164-168.

3. Niebur GL, Feldstein MJ, Yuen JC, et al. High-resolution finite element models with tissue strength asymmetry accurately predict failure of trabecular bone. $J$ Biomech 2000; 33: 1575-1583.

4. Imai K, Ohnishi I, Bessho M, et al. Nonlinear finite element model predicts vertebral bone strength and fracture site. Spine (Phila Pa 1976) 2006; 31(16): 1789-1794.

5. Kayanja MM, Ferrara LA and Lieberman IH. Distribution of anterior cortical shear strain after a thoracic wedge compression fracture. Spine $J$ 2004; 4(1): 76-87.

6. Adams MA, McNally DS and Dolan P. 'Stress' distributions inside intervertebral discs. The effects of age and degeneration. J Bone Joint Surg Br 1996; 78(6): 965-972.

7. Polikeit A, Nolte LP and Ferguson SJ. Simulated influence of osteoporosis and disc degeneration on the load transfer in a lumbar functional spinal unit. $J$ Biomech 2004; 37(7): 1061-1069.

8. Ruberté LM, Natarajan RN and Andersson GB. Influence of single-level lumbar degenerative disc disease on the behavior of the adjacent segments - a finite element model study. J Biomech 2009; 42(3): 341-348.

9. Kurutz M and Oroszváry L. Finite element analysis of weightbath hydrotraction treatment of degenerated lumbar spine segments in elastic phase. J Biomech 2010; 43(3): 433-441.

10. Wilke H-J, Wenger $\mathrm{K}$ and Claes L. Testing criteria for spinal implants: recommendations for the standardization of in vitro stability testing of spinal implants. Eur Spine $J$ 1998; 7: 148-154.

11. Edwards WT, Zheng Y, Ferrara LA, et al. Structural features and thickness of the vertebral cortex in the thoracolumbar spine. Spine (Phila Pa 1976) 2001; 26(2): 218 225.

12. Schmidt H, Heuer F, Claes L, et al. The relation between the instantaneous center of rotation and facet joint forces - a finite element analysis. Clin Biomech (Bristol, Avon) 2008; 23(3): 270-278.

13. Schmidt H, Kettler A, Heuer F, et al. Intradiscal pressure, shear strain, and fiber strain in the intervertebral disc under combined loading. Spine (Phila Pa 1976) 2009; 32(7): 748-755.

14. Tyndyka MA, Barron V, McHugh PE, et al. Generation of a finite element model of the thoracolumbar spine. Acta Bioeng Biomech 2007; 9(1): 35-46.

15. Schmidt $\mathrm{H}$, Heuer $\mathrm{F}$ and Wilke HJ. Which axial and bending stiffnesses of posterior implants are required to design a flexible lumbar stabilization system? $J$ Biomech 2008; 42(1): 48-54.

16. Lu YM, Hutton WC and Gharpuray VM. Do bending, twisting, and diurnal fluid changes in the disc affect the propensity to prolapse? A viscoelastic finite element model. Spine (Phila Pa 1976) 1996; 21(22): 2570-2579.

17. White AA and Panjabi MM. Clinical biomechanics of the spine. Philadelphia, PA: Lippincott Williams \& Wilkins, 1990.

18. Marchand F and Ahmed AM. Investigation of the laminate structure of lumbar disc anulus fibrosus. Spine (Phila Pa 1976) 1990; 15(5): 402-410.

19. Burstein AH, Reilly DT and Martens M. Aging of bone tissue: mechanical properties. J Bone Joint Surg Am 1976; 58(1): 82-86.

20. Lindahl O. Mechanical properties of dried defatted spongy bone. Acta Orthop Scand 1976; 47(1): 11-19.

21. Yamada H and Evans FG. Strength of biological materials. Baltimore, MD: Lippincott Williams \& Wilkins, 1970. 
22. Périé D, Korda D and Iatridis JC. Confined compression experiments on bovine nucleus pulposus and annulus fibrosus: sensitivity of the experiment in the determination of compressive modulus and hydraulic permeability. $J$ Biomech 2005; 38(11): 2164-2171.

23. Shirazi-Adl A, Ahmed AM and Shrivastava SC. A finite element study of a lumbar motion segment subjected to pure sagittal plane moments. J Biomech 1986; 19(4): $331-350$

24. Grant JP, Oxland TR and Dvorak MF. Mapping the structural properties of the lumbosacral vertebral endplates. Spine (Phila Pa 1976) 2001; 26(8): 889-896.

25. Morgan FR. The mechanical properties of collagen fibres: stress-strain curves. J Soc Leather Trades' Chem 1960; 44: 170-179.

26. Little JS and Khalsa PS. Material properties of the human lumbar facet joint capsule. J Biomech Eng 2005; 127(1): 15-24.

27. Elder BD, Vigneswaran K, Athanasiou KA, et al. Biomechanical, biochemical, and histological characterization of canine lumbar facet joint cartilage. Neurosurgery 2010; 66(4): 722-727.

28. RenShape Solutions Casting. Resin - RenCast ${ }^{\circledR}$ FC 53 Isocyanate/FC 53 Polyol, Quick setting polyurethane system. Publication no. T263e GB, November, 2004. Basel: Huntsman Advanced Materials $\mathrm{GmbH}$.

29. MacGregor CW, Symonds J, Vidosic JP, et al. Strength of materials. In: Baumeister $\mathrm{T}$ and Avallone EA (eds) Marks' standard handbook for mechanical engineers. New York: McGraw-Hill, 1996, pp. 2-13.

30. Andresen R, Haidekker MA, Radmer S, et al. CT determination of bone mineral density and structural investigations on the axial skeleton for estimating the osteoporosis-related fracture risk by means of a risk bone. Br J Radiol 1999; 72: 569-578.

31. Kopperdahl DL, Morgan EF and Keaveny TM. Quantitative computed tomography estimates of the mechanical properties of human vertebral trabecular bone. J Orthop Res 2002; 20: 801-805.

32. Iatridis JC, Setton LA, Foster RJ, et al. Degeneration affects the anisotropic and nonlinear behaviors of human annulus fibrosus in compression. J Biomech 1998; 31: $535-544$.

33. Umehara S, Tadano S, Abumi K, et al. Effects of degeneration on the elastic modulus distribution in the lumbar intervertebral disc. Spine (Phila Pa 1976) 1996; 21(7): 811-819.

34. Forwood MR and Vashishth D. Translational aspects of bone quality - vertebral fractures, cortical shell, microdamage and glycation: a tribute to Pierre D. Delmas. Osteoporos Int 2009; 20: S247-S253.

35. Ooms ME, Roos JC, Bezemer PD, et al. Prevention of bone loss by vitamin D supplementation in elderly women: a randomized double-blind trial. J Clin Endocrinol Metab 1995; 80(4): 1052-1058.

36. Cummings SR, Black DM, Thompson DE, et al. Effect of alendronate on risk of fracture in women with low bone density but without vertebral fractures. JAMA 1998; 280(24): 2077-2082.
37. Hongo M, Abe E, Shimada Y, et al. Surface strain distribution on thoracic and lumbar vertebrae under axial compression. The role in burst fractures. Spine (Phila Pa 1976) 1999; 24(14): 1197-1202.

38. Shah JS, Hampson WG and Jayson MI. The distribution of surface strain in the cadaveric lumbar spine. $J$ Bone Joint Surg Br 1978; 60(2): 246-251.

39. Pintar FA, Yoganandan N, Pesigan M, et al. Cervical vertebral strain measurements under axial and eccentric loading. J Biomech Eng 1995; 117(4): 474- 478.

40. Rohlmann A, Bauer L, Zander T, et al. Determination of trunk muscle forces for flexion and extension by using a validated finite element model of the lumbar spine and measured in vivo data. $J$ Biomech 2006; 39(6): 981-989.

41. Noailly J, Wilke HJ, Planell JA, et al. How does the geometry affect the internal biomechanics of a lumbar spine bi-segment finite element model? Consequences on the validation process. J Biomech 2007; 40(11): 2414-2425.

42. Kumaresan S, Yoganandan N, Pintar FA, et al. Finite element modeling of the cervical spine: role of intervertebral disc under axial and eccentric loads. Med Eng Phys 1999; 21(10): 689-700.

43. Ayturk UM and Puttlitz CM. Parametric convergence sensitivity and validation of a finite element model of the human lumbar spine. Comput Meth Biomech Biomed Eng 2011; 14(8): 695-705.

44. Whyne CM, Hu SS, and Lotz JC. Burst fracture in the metastatically involved spine: development, validation, and parametric analysis of a three-dimensional poroelastic finite-element model. Spine (Phila Pa 1976) 2003; 28(7): 652-660.

45. Ashman RB, Cowin SC, Van Buskirk WC, et al. A continuous wave technique for the measurement of the elastic properties of cortical bone. J Biomech 1984; 17(5): 349-361.

46. Keaveny TM and Hayes WC. A 20-year perspective on the mechanical properties of trabecular bone. $J$ Biomech Eng 1993; 115(4B): 534-542.

47. Klisch SM and Lotz JC. A special theory of biphasic mixtures and experimental results for human annulus fibrosus tested in confined compression. J Biomech Eng 2000; 122(2): 180-188.

48. Schwiedrzik JJ and Zysset PK. An anisotropic elasticviscoplastic damage model for bone tissue. Biomech Model Mechanobiol. Epub ahead of print 18 April 2012. DOI: 10.1007/s10237-012-0392-9.

49. Malandrino A, Noailly J and Lacroix D. Regional annulus fibre orientations used as a tool for the calibration of lumbar intervertebral disc finite element models. Comput Meth Biomech Biomed Eng. Epub ahead of print 6 January 2012. DOI: 10.1080/10255842.2011.644539

50. Cloyd JM, Malhotra NR, Weng L, et al. Material properties in unconfined compression of human nucleus pulposus, injectable hyaluronic acid-based hydrogels and tissue engineering scaffolds. Eur Spine J 2007; 16: 1892-1898.

51. Frobin W, Brinckmann P, Kramer M, et al. Height of lumbar discs measured from radiographs compared with degeneration and height classified from MR images. Eur Radiol 2001; 11(2): 263-269. 